Report No。BMI-1355

UC-25 Metallurgy and Ceramics (TID-4500, 14th Ed.)

Contract No. W-7405-eng-92

FATIGUE STUDIES OF INCONEL

by

Raymond $\mathrm{G}$. Carlson

June 26, 1959

BATTELLE MEMORIAL INSTITUTE

505 King Avenue

Columbus 1, Ohio 


\section{DISCLAIMER}

This report was prepared as an account of work sponsored by an agency of the United States Government. Neither the United States Government nor any agency Thereof, nor any of their employees, makes any warranty, express or implied, or assumes any legal liability or responsibility for the accuracy, completeness, or usefulness of any information, apparatus, product, or process disclosed, or represents that its use would not infringe privately owned rights. Reference herein to any specific commercial product, process, or service by trade name, trademark, manufacturer, or otherwise does not necessarily constitute or imply its endorsement, recommendation, or favoring by the United States Government or any agency thereof. The views and opinions of authors expressed herein do not necessarily state or reflect those of the United States Government or any agency thereof. 


\section{DISCLAIMER}

Portions of this document may be illegible in electronic image products. Images are produced from the best available original document. 
TABLE OF CONTENTS

Page

\begin{abstract}
. . . . . . . . . . . . . . . . . . . . . 1
INTRODUCTION • . . . . . . . . . . . . . . . . . . . . . 1

EXPERIMENTAL WORK . . . . . . . . . . . . . . . . 2

Material . . . . . . . . . . . . . . . . . . . . 2

Specimens . . . . . . . . . . . . . . . . . . . . . 4

Equipment and Experimental Procedure . . . . . . . . . . . 4

EXPERIMENTAL RESULTS • • . . . . . . . . . . . . . . . . . 6

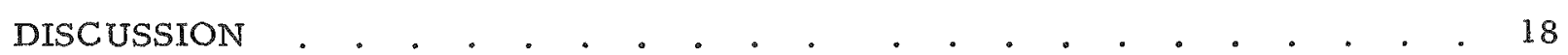

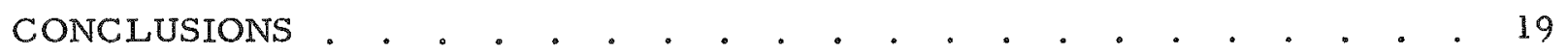

REFERENCES • . . . . . . . . . . . . . . . . . . . . 19
\end{abstract}




\title{
FATIGUE STUDIES OF INCONEL
}

\author{
Raymond G. Carlson
}

\begin{abstract}
As part of a broad ORNL program to investigate the complex nature of deformation and fracture in materials stressed at elevated temperature, the fatigue properties of Inconel were studied. Axial-load fully alternating fatigue tesis were performed in the range 1300 to $1500 \mathrm{~F}$, for frequencies of 6 and $60 \mathrm{cpm}$. Continuous traces of load and strain were made to determine relationships between stress, strain, and lifeime, for lifetimes within the range of $10^{3}$ and $10^{5}$ cycles.

The data obtained indicate that fatigue strength, whether measured in stress, total strain, or plastic strain, is a function of both temperature and frequency. It was found that the relationship betueen stress and strain varies with cycles of stress reversal, never reaching an equilibrium condition. In addition, the strain behavior of a specimen during stress cycling is not continuous. Strain in the plastic region was found to occur in sudden, steplike increments which are predictable functions of temperature, stress, frequency, and cycles.
\end{abstract}

\section{INTRODUCTION}

To provide better design criteria for nuclear reactors, Oak Ridge National Laboratory has been investigating the complex nature of deformation and fracture in materials stressed at elevated temperatures. In some cases, reactor components are subjected to cyclic stresses from external load sources. In other cases, cyclic stresses may arise from thermal fluctuations superimposed on steady-state thermal conditions. The frequency of these mechanically and thermally induced stresses may be low and hence creep and relaxation may occur. It is believed that a broader understanding of the deformation and fracture behavior of the materials of interest will lead to more rational design approaches to some of the complex stress conditions that the reactor designer encounters.

The project at Battelle Memorial Institute represents only a part of the research program in this area being conducted by the ORNL Metallurgy Division. This broad program is concerned with the interrelationships of stress or strain fatigue, thermal fatigue, and creep relaxation of materials. Some of this work has been reported by ORNL. (1)

The Battelle phase of the program, summarized in this report, was concerned with measuring and recording stress and strain in Inconel specimens under elevatedtemperature fully alternating stress-cycling conditions, and with determining the relationships among the variables of temperature, stress, strain, lifetime, and cyclic frequency.

To develop pertinent fatigue data, stress-cycling tests were perforned for three conditions: (1) $1500 \mathrm{~F}$ at $60 \mathrm{cpm}$, (2) $1300 \mathrm{~F}$ at $60 \mathrm{cpm}$, and (3) $1500 \mathrm{~F}$ at $6 \mathrm{cpm}$. The Inconel specimens were subjected to fully alternating cyclic stresses of

(1) References at end. 
magnitudes which would produce failures in the specimens within the lifetime range of $10^{3}$ to $10^{5}$ cycles. During the course of each test, continuous traces were made of cyclic load against time and of cyclic strain against time. From these traces, stressstrain hysteresis curves could be plotted. From the traces and the hysteresis curves, the pertinent relationships between stress, strain, and cycles could be obtained.

\section{EXPER IMENTAL WORK}

\section{Material}

The Inconel evaluated in this program was hot-rolled annealed bar stock $1-1 / 4$ in. in diameter. A typical microstructure is shown in Figure 1. The macrostructure (Figure $2 a$ ) of the as-received material showed a columnar grain structure near the surface of the bar. Reannealing the material at $1900 \pm 20 \mathrm{~F}$ for $1 \mathrm{hr}$ homogenized the structure (Figure $2 \mathrm{~b}$ ).

$50 \mathrm{x}$

N36672

Etchant: Aqua Regia Superimposed on 20 Glycerin, $20 \mathrm{HCl}$, and $3 \mathrm{HNO}_{3}$

FIGURE 1. AS-RECEIVED MICROSTRUCTURE OF INCONEL BAR STOCK

The chemical analysis as supplied by the vendor was as follows:

Alloy Composition, w/o

\begin{tabular}{llllllll}
$\mathrm{C}$ & $\mathrm{Mn}$ & $\mathrm{Ee}$ & $\mathrm{S}$ & $\mathrm{Si}$ & $\mathrm{Cu}$ & $\mathrm{Ni}(\mathrm{a})$ & $\mathrm{Cr}$ \\
\hline 0.02 & 0.17 & $\frac{\mathrm{Su}}{7.33}$ & 0.19 & $\frac{0.13}{76.20}$ & $\frac{15.93}{0.19}$
\end{tabular}

(a) Percentage of nickel includes a small amount of cobalt.

Elevated-temperature tensile tests were performed on the material to establish the tensile properties of the Inconel material used. The data obtained are shown in Table 1 . 


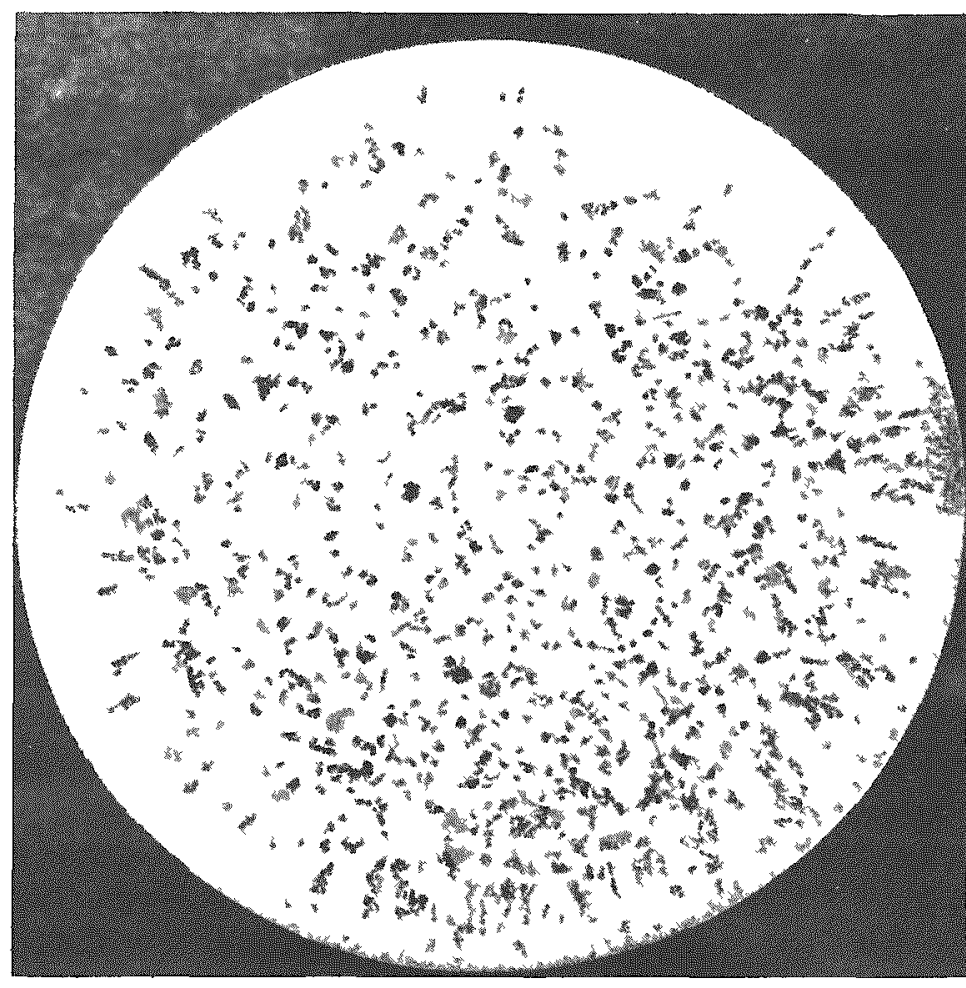

$3 x$

N36675

a. As-Received Material

b. After Reannealing $1 \mathrm{Hr}$ at $1900 \pm 20 \mathrm{~F}$

$3 x$

Marble's Etchant

N36916

FIGURE 2. MACROSTRUCTURE OF INCONEL BAR STOCK EVALUATED

The material was hot rolled and annealed by the vendor and, as received, displayed a columnar grain structure near the surface. The homogenization effected by the second annealing can be seen in the lower photograph. 
TABLE 1. RESULTS OF TENSILE TESTS ON INCONEL MATERIAL USED FOR SPECIMEN FABRICATION

0.3-In.-Diameter Bars Were Tested at a Strain Rate of $0.003 \mathrm{In} . / \mathrm{In} . / \mathrm{Min}$

\begin{tabular}{lcc}
\hline & At $1200 \mathrm{~F}$ & At $1600 \mathrm{~F}$ \\
\cline { 2 - 2 } Tensile Strength, psi & 58,500 & 17,400 \\
$\begin{array}{l}0.2 \text { Per Cent Offset Yicld Strength, } \\
\text { psi }\end{array}$ & 17,300 & 14,700 \\
Elongation in $1 \mathrm{In}$, per cent & 47 & 99 \\
Reduction in Area, per cent & 52 & 95 \\
Modulus of Elasticity, $10^{6}$ psi & 21.2 & 14.7 \\
\hline
\end{tabular}

\section{Specimens}

The two specimen configurations used in the investigation are shown in Figure 3. The longer specimen was employed for the majority of the studies. However, for some of the studies at $1500 \mathrm{~F}$ and $6 \mathrm{cpm}$, it was necessary to use a shorter specimen to minimize buckling at high stress levels. Several of the short specimens were studied at low stresses as well, to compare them with the long specimens. No significant difference was found in the results for the two configurations at low stress levels.

The specimens contained a hole at each end, into which a pointed probe was inserted. This probe was attached to the strain-measuring device. The strain or elongation of the specimen which was measured was, therefore, the change in length of the specimen between the bottoms of the two holes. This distance was 2.000 in. nominally for the longer specimen. However, to compensate for the fact that the 2-in. gage length extends into the radiused section of the specimen, an effective nominal gage length of $1.923 \mathrm{in}$. was used in computing strain. The corresponding figure used for the short specimens was $1.173 \mathrm{in.}$ This effective gage length was determined by assuming uniaxial elastic behavior in the radiused region. This gives only an approximation of the effective gage length, especially when the specimen undergoes plastic deformation. However, it is believed that the error introduced by this method of calculating the gage length is not very great.

\section{Equipment and Experimental Procedure}

Fatigue studies were carried out on a 5000-1b-capacity Krouse axial-1oad fatiguetesting machine. This was equipped with a variable-speed drive which enabled the machine to be operated at 6 and $60 \mathrm{cpm}$. The machine was also equipped with a hydraulic load maintainer. This hydraulic system maintained a zero mean load on the specimens during heating and actual testing. 


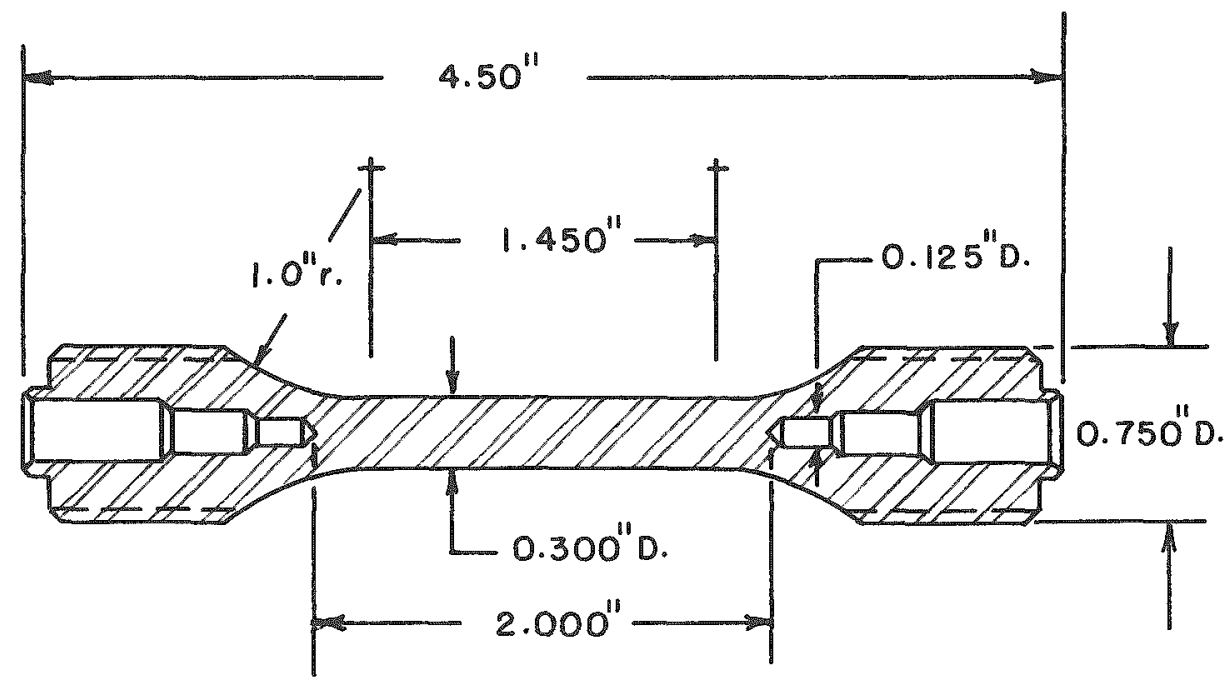

a Long Specimen

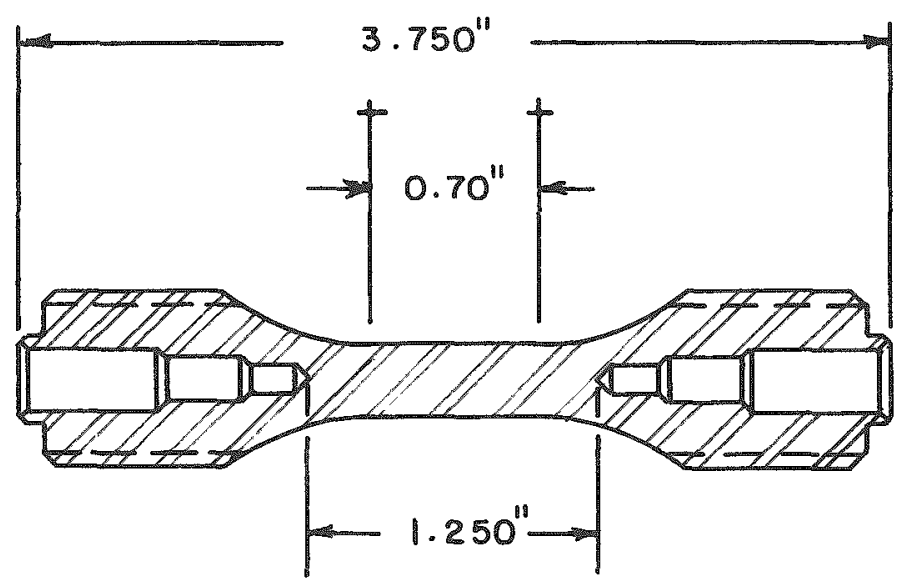

b Short Specimen

A -31578

FIGURE 3. INCONEL AXIAL-LOAD FATIGUE SPECIMEN CONFIGURATION 
To measure the load on the specimens a load cell was placed in series with the specimen. The load cell contained four Bakelite SR-4 strain gages wired into a fourarm bridge. Strain was measured by means of an extensometer consisting of two beryllium-copper C-shaped clips. Two Bakelite SR-4 strain gages were fixed to each extensometer. Figure 4 shows the extensometer system linked to a specimen. In this illustration, the resistance-wire-wound furnace used to heat the specimen has been lowered to expose the specimen. The glass-wool-protected beryllium-copper clips are shown in the upper section of the photo.

Hollow specimen grips are employed to allow passage of the probe seated in the hole in each end of the specimen. Each probe is coupled by two long rods with one of the movable plates. Two tension springs between the two plates supply the force needed to seat the probes in the specimen holes. The beryllium-copper extensometer clips are connected between the two movable plates. Deformation of the specimen transmitted through the probes to the plates causes movement of the plates and a deflection of the two clips. This deflection is measured by the SR-4 strain gages. By careful mounting of the clips, it was possible to obtain a linear relation between straingage output and specimen deflection. Sensitivity was such that deflections on the order of $10 \mu \mathrm{in}$. could easily be read.

The load cell and extensometer were connected to a Sanborn two-channel recorder. This recorder plotted both load and strain against time. From these plots, stress-strain hysteresis curves, and other stress and strain data could be obtained.

Also shown in Figure 4 are the thermocouples used to measure specimen temperature. These thermocouples were connected to controls which regulated the furnace temperature. During the test, the temperature was maintained within approximately $\pm 5 \mathrm{~F}$.

A similar procedure was used for all tests. A specimen was mounted in the grips which were then installed in the Krouse machine. Thermocouples and extensometer rods were attached. The machine was then adjusted to supply the required alternating load to the specimen. Then a small number of cycles were run at room temperature to determine the exact load applied to the specimen. Load and strain traces of these cycles were recorded on the Sanborn recorder. At higher loads, some plastic deformation of the specimens occurred at room temperature, but at lower loads the strain was wholly elastic. The specimens were brought to temperature and heated overnight (for approximately $16 \mathrm{hr}$ ). The test was then started. Continuous traces of load and strain were made during the entire specimen lifetime.

\section{EXPERIMENTAL RESULTS}

Fully-alternating stress-cycling fatigue tests were performed for three temperature and frequency conditions: (1) $1500 \mathrm{~F}$ at $60 \mathrm{cpm}$, (2) $1300 \mathrm{~F}$ at $60 \mathrm{cpm}$, and (3) $1500 \mathrm{~F}$ at $6 \mathrm{cpm}$. While there are many parameters which could be evaluated from the stress and strain data obtained, it was decided that a study of the relationships among the variables of stress range, total strain range, plastic strain, frequency, and temperature would provide the most useful information. Stress-range and total- 


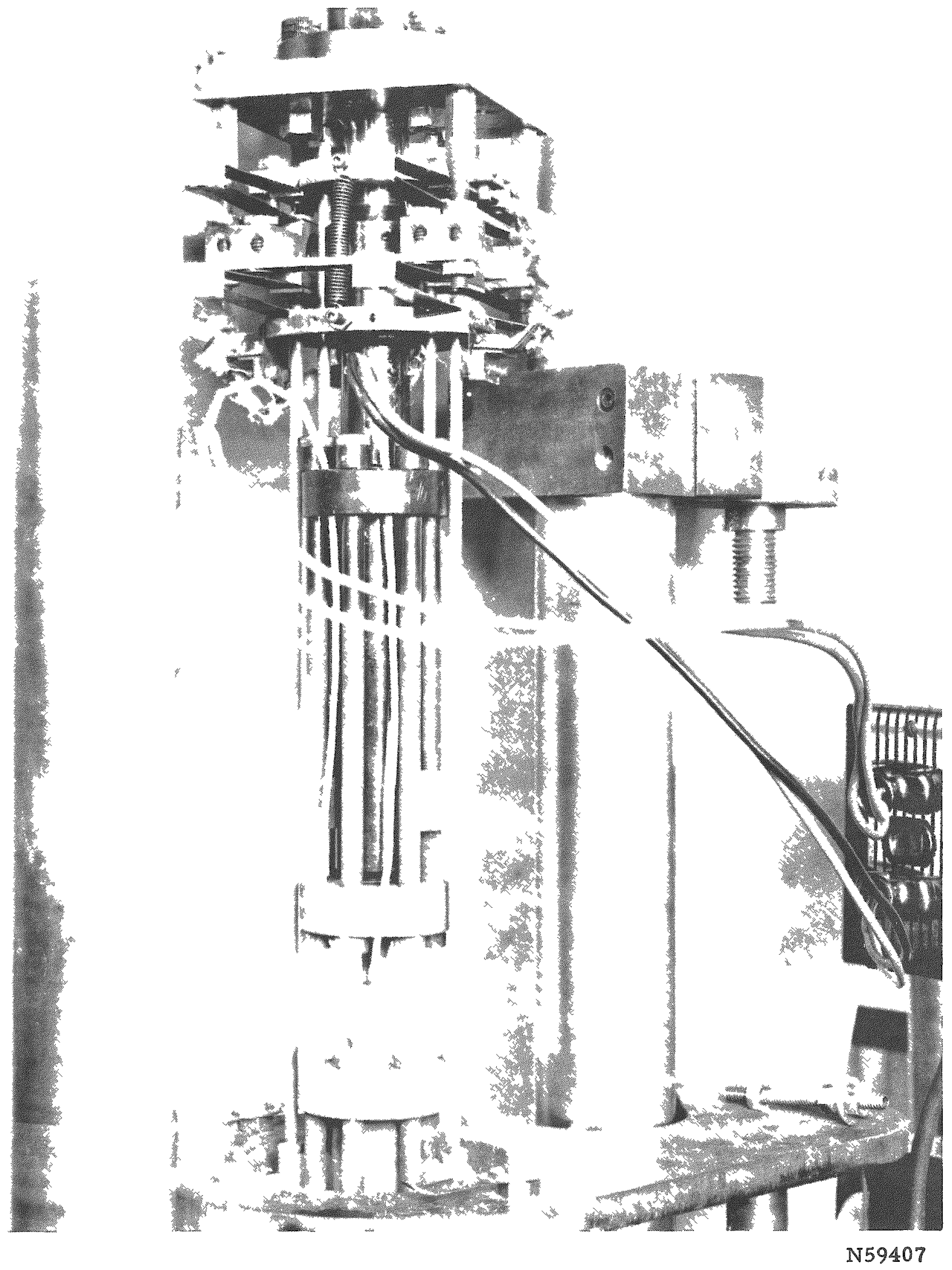

FIGURE 4. EXTENSOMETER USED FOR MEASUREMENT OF CYCIIC STRAINS IN INCONEL 
strain-range data were taken directly from the stress-against-time and the strainagainst-time traces obtained from the Sanborn recorder. To develop plastic-strain data, it was necessary to plot stress-strain hysteresis curves. The plastic strain per cycle was defined as the width of the hysteresis curve at zero stress. These plots were made for a number of typical cycles for each test performed. A typical hysteresis curve is shown in Figure 5. Here, the plastic strain per cycle is the difference between the strains at Points $A$ and $B$.

For each specimen, plots were made of total strain and plastic strain against cycles for the entire lifetime of the specimen. A typical plot is seen in Figure 6. These plots showed that for a constant stress range the strain range varied during the lifetime of the specimen. During the early cycles, strain hardening occurred which caused a large decrease in the strain range. For the remainder of the specimen life, the strain range gradually increased. This increase was found to be approximately linear until the specimen approached failure. The strain range then increased rapidly until the test was stopped. This rapid increase is believed to be due to the opening of macroscopic cracks in the specimens. The point of failure might be considered to be the point at which this deviation from linearity occurred, if cracks did appear at that time. However, failure was considered to occur when the fatigue machine automatically turned off because of inability of the specimen to carry a load. The percentage difference in lifetime between the two points was not large, except for very-shortlifetime tests.

Although this type of strain behavior was found for almost all specimens, there was some variation in strain behavior under certain conditions. For tests at $1300 \mathrm{~F}$, the initial period of decreasing strain extended over a much larger number of cycles than it did for tests at $1500 \mathrm{~F}$. It was also found that the low-stress-level tests at $1500 \mathrm{~F}$ and $6 \mathrm{cpm}$ did not show an initial decrease in strain range. Instead, the linear increase in strain began with the first few cycles. These variations indicate that the strain behavior during the initial cycles is probably a function of strain rate and temperature.

Since strain varied continuously during the life of the specimen, it was necessary to define an average strain value for use in furthex analyses. As the strain increased linearly with cycles during the major portion of the specimen lifetime, the strain at half the total life was used. Because of the large strains occurring at the beginning and end of a test, this value would, in general, be slightly less than an arithmetical average of the strain range for each cycle. The plastic-strain range and the totalstrain range at half the total lifetime are, therefore, the values recorded in Tables 2 through 4 , which summarize the data obtained from this study.

Complete curves of total strain against cycles were drawn for each specimen. However, for most tests, hysteresis curves were drawn only for cycles in the general range of half the lifetime. Because of variations between strain cycles due largely to discontinuities in the strain behavior, the plastic-strain value obtained from a small number of hysteresis curves are subject to greater error and scatter than the total strain data. Further analysis of additional stress-strain hysteresis curves to define more accurately the average plastic strain might be useful to confirm the results of this program. 


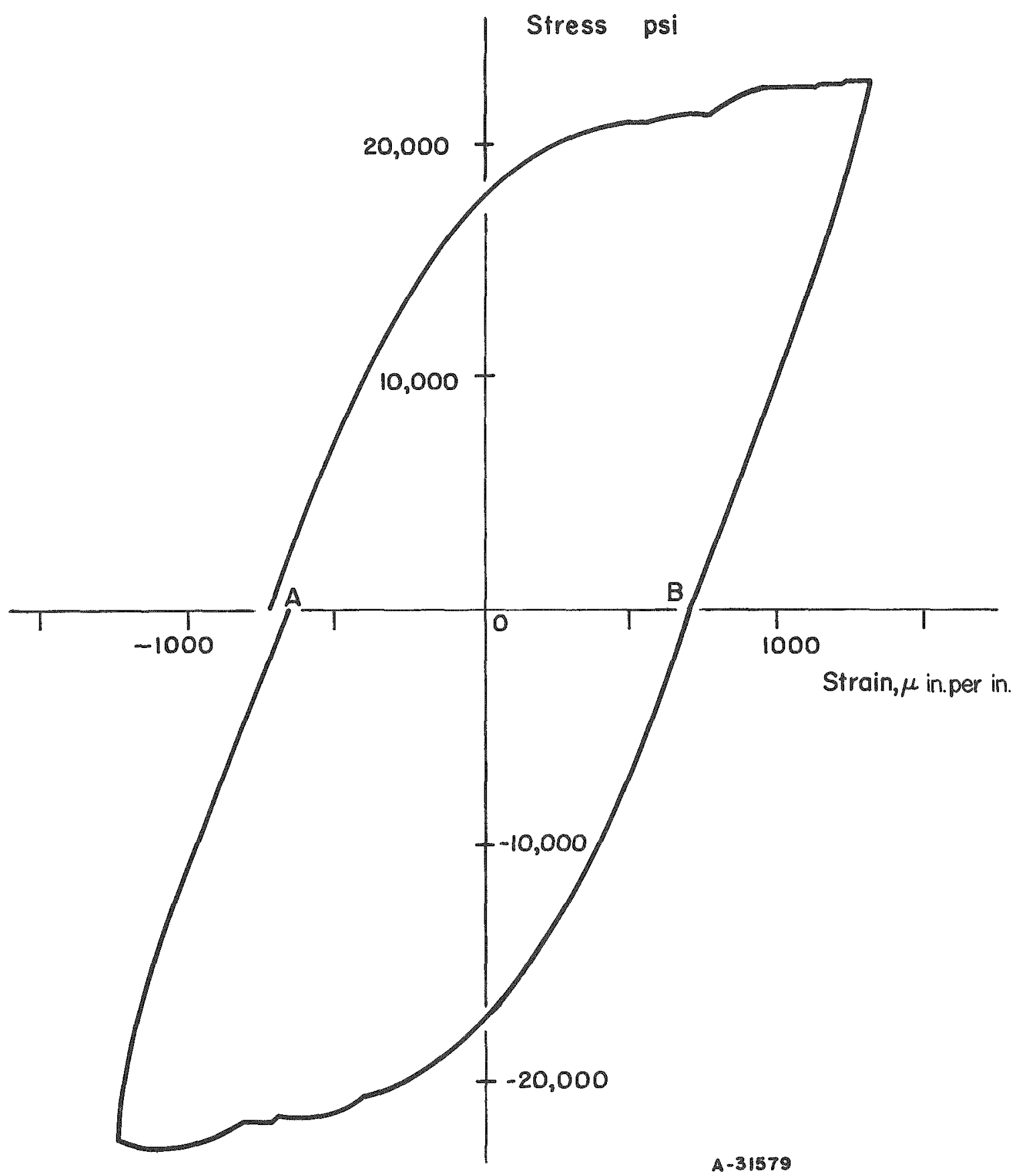

FIGURE 5. TYPICAL STRESS-STRAIV HYSTERESIS CURVE

Shown here is the third cycle on Specimen 6-24. 


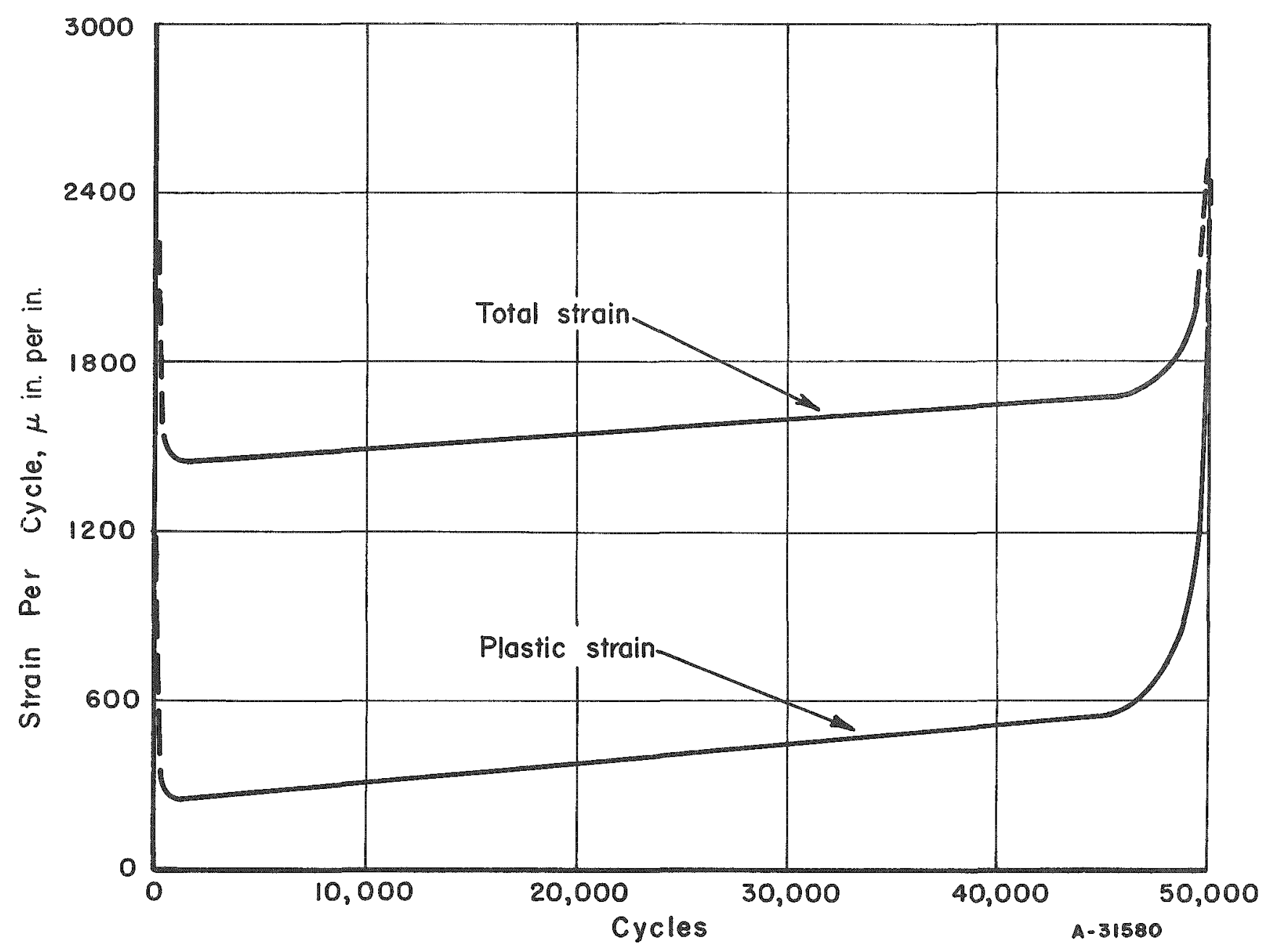

FIGURE 6. TYPICAL CURVES SHOWING VARIATION OF PLASTIC STRAIN AND TOTAL STRAIN WITH LIFETIME (SPECIMEN 11-3) 
TABLE 2. RESULTS OF STRESS-CYCLING TESTS OF INCONEL A T 1500 F AND 60 CPM

\begin{tabular}{|c|c|c|c|c|c|c|c|c|}
\hline \multirow[b]{2}{*}{ Specimen } & \multirow[b]{2}{*}{ Diameter, in. } & \multicolumn{2}{|c|}{ Gage Length, in. } & \multirow{2}{*}{$\begin{array}{c}\text { Stress, } \\
\text { psi }\end{array}$} & \multicolumn{2}{|c|}{ Strain, Hin. per in. } & \multirow{2}{*}{$\begin{array}{c}\text { Lifetime, } \\
\text { cycles }\end{array}$} & \multirow[b]{2}{*}{ Remarks } \\
\hline & & Measured & Effective & & Total & Plastic & & \\
\hline $2-28$ & 0.2945 & 1.999 & 1.923 & 17,800 & 1544 & 320 & 68,200 & \\
\hline $11-3$ & 0.3008 & 2 nominal & 1.923 & 17,000 & 1736 & 409 & 50,100 & \\
\hline $4-37$ & 0.2950 & 2.000 & 1.923 & 18,750 & 1571 & 243 & 42,370 & \\
\hline $9-30$ & 0.2942 & 2 nominal & 1.923 & 18,500 & 1705 & 411 & 19,400 & $\begin{array}{l}\text { Temperature dropped to } \\
1370 \mathrm{~F} \text { during } \\
\text { test, then was corrected } \\
\text { to } 1500 \mathrm{~F}\end{array}$ \\
\hline $9-23$ & 0.2998 & 1.996 & 1.921 & 19,000 & 1798 & 467 & 16,100 & \\
\hline $7-38$ & 0.2995 & 2 nominal & 1.923 & 18,500 & 1953 & 1104 & 8,900 & \\
\hline $9-38$ & 0.3000 & 1.950 & 1.898 & 20,000 & 2350 & 925 & 6,300 & \\
\hline $1-1$ & 0.3018 & 2 nominal & 1.923 & 22,000 & 2300 & 1398 & 5,400 & $\begin{array}{l}\text { Temperature dropped } \\
\text { below } 1485 \mathrm{~F} \text { during test, } \\
\text { then was corrected to } \\
1500 \mathrm{~F}\end{array}$ \\
\hline
\end{tabular}


TABLE 3. RESULTS OF STRESS-CYCLING TESTS OF INCONEL AT $1300 \mathrm{~F}$ AND 60 CPM

\begin{tabular}{|c|c|c|c|c|c|c|c|}
\hline \multirow[b]{2}{*}{ Specimen } & \multirow[b]{2}{*}{ Diameter, in. } & \multicolumn{2}{|c|}{ Gage Length, in. } & \multirow[b]{2}{*}{ Stress, psi } & \multicolumn{2}{|c|}{ Strain, Min. per in. } & \multirow{2}{*}{$\begin{array}{c}\text { Lifetime } \\
\text { cycles }\end{array}$} \\
\hline & & $\overline{\text { Measured }}$ & Effective & & Total & Plastic & \\
\hline $13-22$ & 0.3012 & 1.998 & 1.922 & 26,000 & 2195 & 288 & 184,000 \\
\hline $6-26$ & 0.2955 & 2.002 & 1.924 & 27,000 & 2230 & 289 & 55,460 \\
\hline $1-21$ & 0.2972 & 2.003 & 1.924 & 28,000 & 2430 & 394 & 22,500 \\
\hline $9-18$ & 0.3001 & 2.000 & 1.923 & 26,500 & 2315 & 358 & 22,370 \\
\hline $6-45$ & 0.2994 & 1.998 & 1.922 & 28,500 & 2425 & 501 & 14,720 \\
\hline $12-11$ & 0.3008 & 1.999 & 1.923 & 28,250 & 2505 & 518 & 14,000 \\
\hline $1-18$ & 0.2983 & 1.999 & 1.923 & 29,000 & 2945 & 854 & 6,100 \\
\hline
\end{tabular}


TABLE 4. RESULTS OF STRESS-CYCIING TESTS OF INCONEL AT 1500 F AND 6 CPM

\begin{tabular}{|c|c|c|c|c|c|c|c|}
\hline \multirow[b]{2}{*}{ Specimen } & \multirow[b]{2}{*}{ Diameter, in. } & \multicolumn{2}{|c|}{ Gage Length, in. } & \multirow[b]{2}{*}{ Stress, psi } & \multicolumn{2}{|c|}{ Strain, $\mu$ in. per in. } & \multirow{2}{*}{$\begin{array}{c}\text { Lifetime, } \\
\text { cycles }\end{array}$} \\
\hline & & Measured & Effective & & Total & Plastic & \\
\hline $2-41$ & 0.2943 & 1.998 & 1.922 & 17,000 & 1,465 & 260 & 17,240 \\
\hline $8-21$ & 0.302 & 1.250 & 1.173 & 16,500 & 1,415 & 280 & 14,400 \\
\hline $2-30$ & 0.2900 & 2.004 & 1.925 & 17,500 & 1,700 & 727 & 8,481 \\
\hline $1-45$ & 0.2995 & 2.000 & 1.923 & 18,000 & 1,835 & 553 & 5,800 \\
\hline $10-40$ & 0.2975 & 1.246 & 1.171 & 19,000 & 2,055 & 769 & 4,800 \\
\hline $11-20$ & 0.3026 & 1.249 & 1.173 & 19,500 & 2,030 & 560 & 4,151 \\
\hline $8-18$ & 0.2996 & 1.999 & 1.923 & 18,500 & 1,980 & 851 & 3,770 \\
\hline $2-4$ & 0.3012 & 1.998 & 1.922 & 19,000 & 2,120 & 957 & 2,968 \\
\hline $3-35$ & 0.3017 & 1.254 & 1.175 & 20,500 & 2,670 & 1,372 & 2,570 \\
\hline $6-24$ & 0.3004 & 1.252 & 1.174 & 22,500 & 2,800 & 1,760 & 2,088 \\
\hline $4-48$ & 0.3012 & 1.2505 & 1.173 & 25,000 & 3,670 & 2,140 & 1,351 \\
\hline
\end{tabular}


The data in the tables were plotted to investigate significant relationships. Figure 7 is a plot of stress against lifetime for all three test conditions. These curves show that fatigue strength, as measured by stress range, decreases as the temperature increases. In addition, frequency is shown to affect fatigue strength. At $1500 \mathrm{~F}$, for a given stress range a specimen cycled at $60 \mathrm{cpm}$ had a longer lifetime in cycles than a specimen cycled at $6 \mathrm{cpm}$.

In Figure 8 the data have been plotted as total strain and plastic strain against lifetime. The plots of total strain against lifetime show the same general relationships found from the stress-lifetime curves. For a given average total-strain range, specimens evaluated at $1300 \mathrm{~F}$ had longer lifetimes than specimens tested at $1500 \mathrm{~F}$. In addition, at $1500 \mathrm{~F}$, specimens cycled at $60 \mathrm{cpm}$ had longer lifetimes, for a given totalstrain range, than specimens cycled at $6 \mathrm{cpm}$.

The plastic-strain data show a somewhat different relationship. For a given average plastic-strain range, the lifetimes of specimens evaluated at $1500 \mathrm{~F}$ and $60 \mathrm{cpm}$ were greater than the lifetimes of specimens cycled at $60 \mathrm{cpm}$ at $1300 \mathrm{~F}$. At $1500 \mathrm{~F}$, specimens cycled at $6 \mathrm{cpm}$ had shortex lifetimes for a given plastic-strain range than specimens cycled at $60 \mathrm{cpm}$.

These relationships appear to be valid, although the scatter of the plastic-strain data for the $60-\mathrm{cpm}$ tests makes it difficult to draw curves for the evaluations at $1500 \mathrm{~F}$ and $60 \mathrm{cpm}$ and $1300 \mathrm{~F}$ and $60 \mathrm{cpm}$. For both conditions, straight-line relationships on a $\log -\log$ plot were assumed and lines having a slope of -0.5 were fitted to the data. This relation between lifetime and plastic strain was suggested by the work of Coffin (2), who has has used the relationship

$$
N^{1 / 2} \Delta \varepsilon_{\rho}=K
$$

where

$$
\begin{aligned}
N & =\text { lifetime in cycles } \\
\Delta \epsilon_{\rho} & =\text { plastic-strain range } \\
K & =\text { a constant. }
\end{aligned}
$$

This relation fitted the data fairly well. A straight line having a different slope was used to fit the plastic-strain data for the evaluation at $1500 \mathrm{~F}$ and $6 \mathrm{cpm}$. Here, a line having a slope of -0.878 fitted the data better.

The straight-line relations assumed give the following results when the general equation $\left(N^{\alpha} \Delta \epsilon_{\rho}=K\right)$ is used:

$\begin{array}{ccc}\frac{\text { Condition }}{1500 \mathrm{~F} \text { at } 60 \mathrm{cpm}} & \frac{\alpha}{0.5} & \frac{\mathrm{K}}{0.077} \\ 1500 \mathrm{~F} \text { at } 6 \mathrm{cpm} & 0.878 & 1.203 \\ 1300 \mathrm{~F} \text { at } 60 \mathrm{cpm} & 0.5 & 0.063\end{array}$

Howevex, the results of this program do not necessarily support the validity of this equation. Examination of Figure 8 shows that, while the straight lines may fit the plasticstrain data fairly well, lines having curvatures concave upward would probably fit the data more closely, expecially the 60-cpm data. 


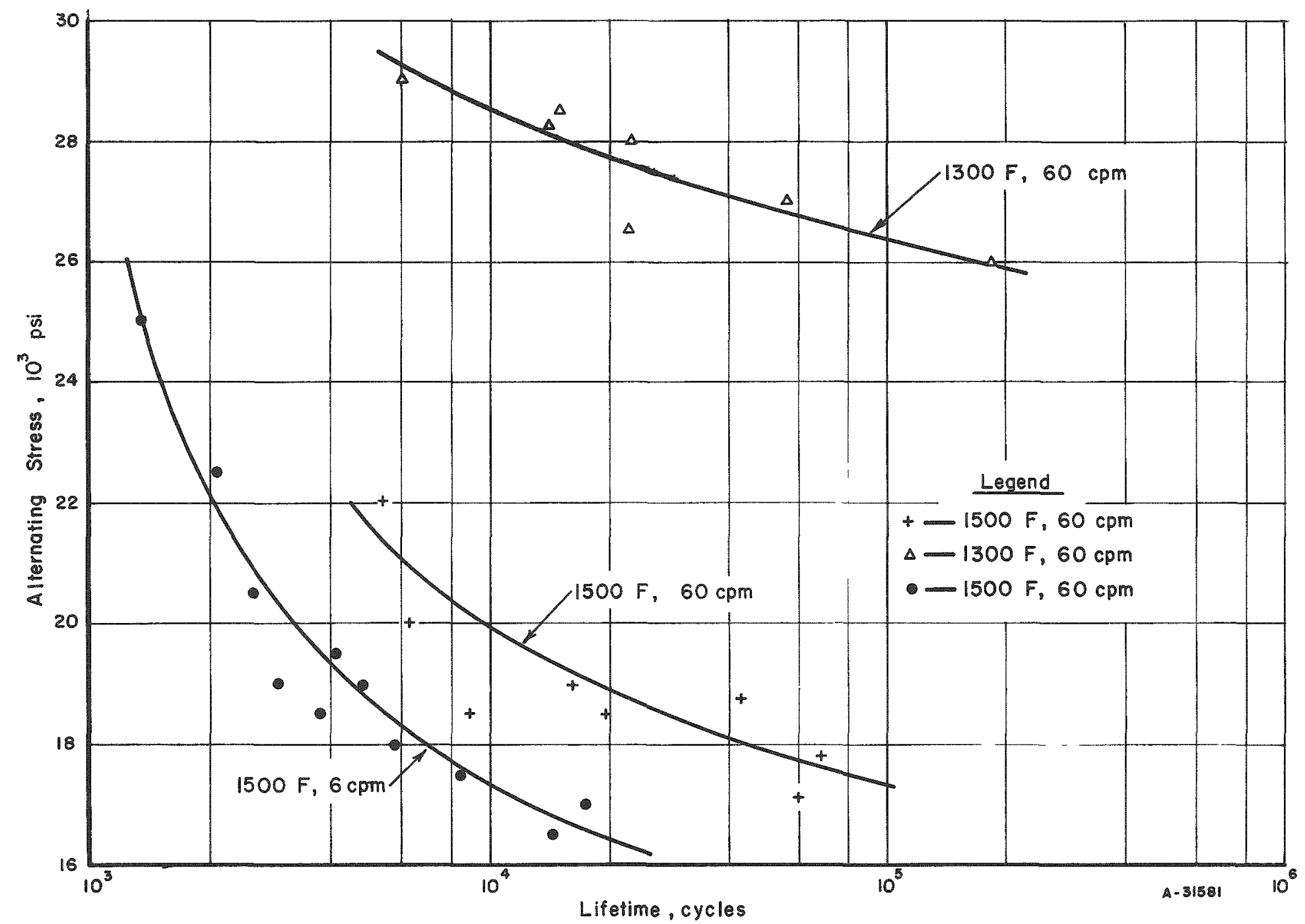

FIGURE 7. STRESS-LIFETIME RELATIONSHIPS FOR FATIGUE OF INCONEL UNDER FULIY REVERSED AXIAL-LOAD CONDITIONS 


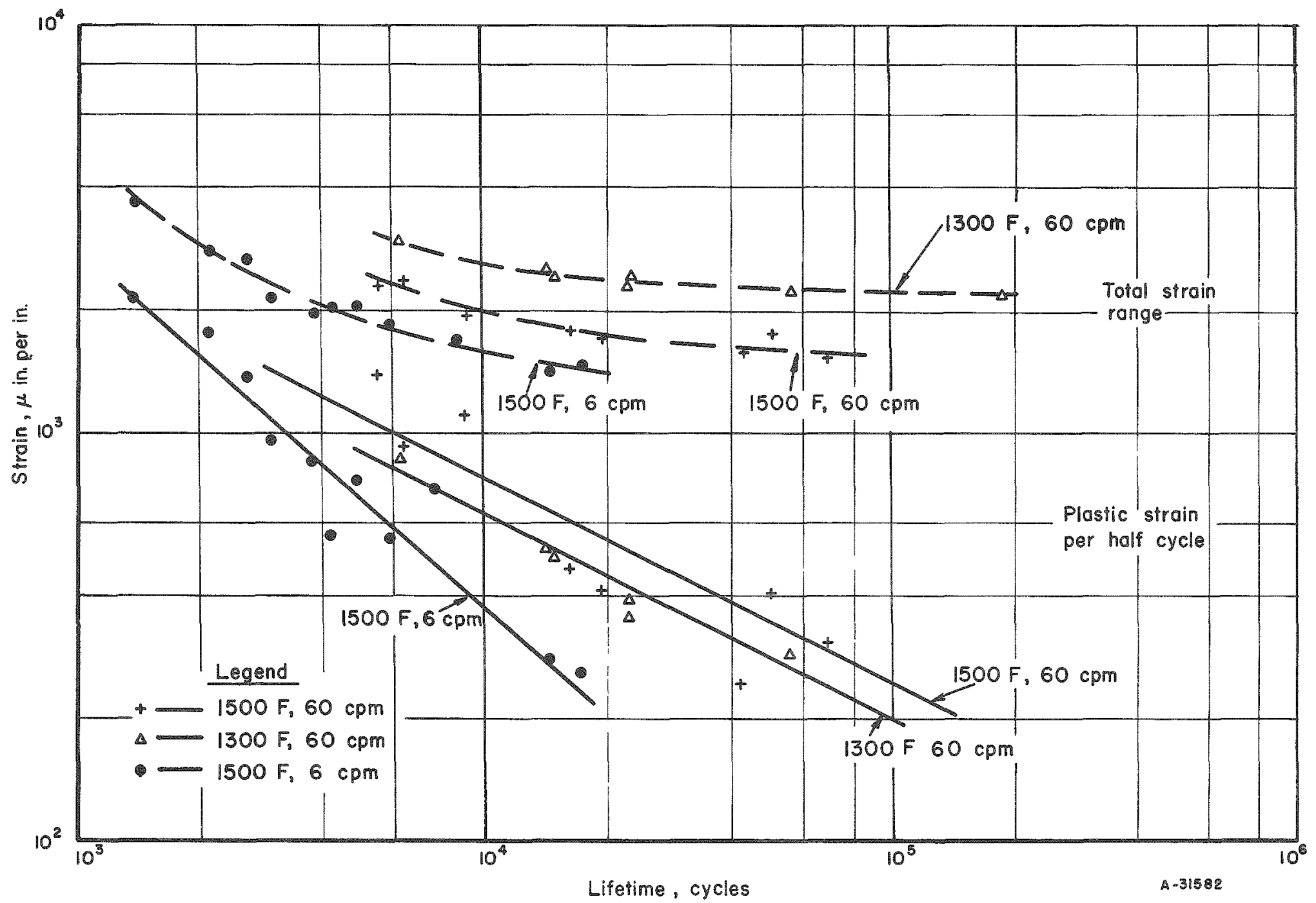

FIGURE 8. STRAIN-LIFETIME RELATIONSHIPS FOR FATIGUE OF INCONEL UNDER FULLY REVERSED AXIAL-LOAD CONDITIONS 


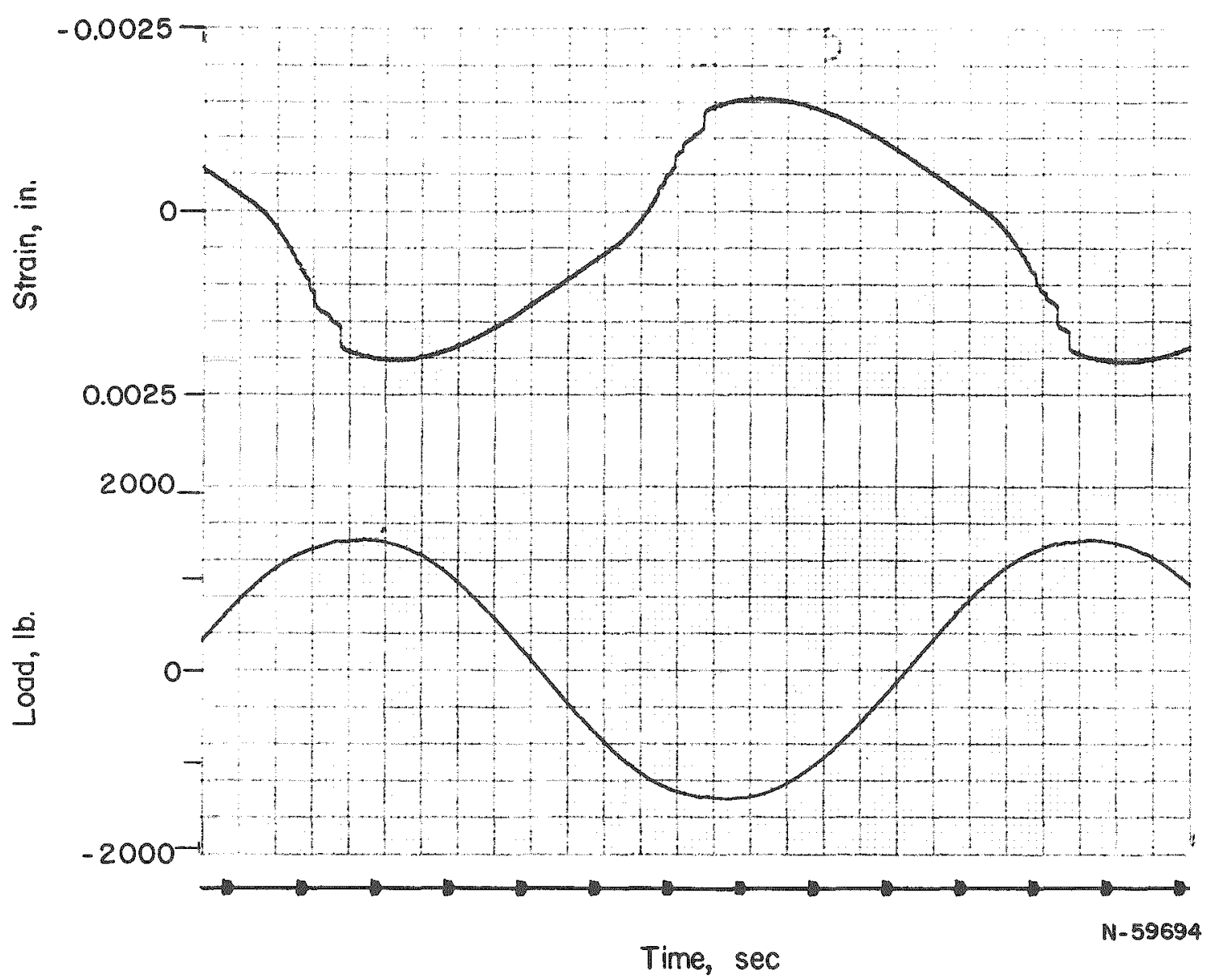

FIGURE 9. DISCONTINUITY IN STRAIN OBSERVED DURING STRESS CYCLING

This typical section of the strain and load trace produced by the Sandborn recorder shows the steplike plastic strain behavior encountered in most tests. The third cycle of Specimen 6-24 is reproduced here. 
DISCUSSION

The use of a measuring system which continuously recorded stress and strain data brought out some interesting observations concerning the behavior of a specimen under fatigue loading. It was found that the relation between stress range and strain range varied continuously in a consistent manner throughout the life of a specimen. Thus, for stress-cycling fatigue tests, there does not exist an "equilibrium condition" for the stress-strain relationship. Instead, the relationship depends upon the number of fatigue cycles to which the specimen is subjected, with the hysteresis curve changing with every cycle. Whether this would hold for longer lifetime tests is not known。

Another phenomenon found was the discontinuity in the strain behavior during stress cycling. Figure 9 illustrates a section of a typical trace of strain against time. Notice that the strain curve is not smooth, but rather it is seen that strains in the plastic region occur in a number of sudden jumps, some of which are quite large. These steps are also seen in Figure 5 which shows the same cycle plotted as stress against strain. This steplike behavior was observed in most tests. A careful check was made of the strain-measuring system to determine whether the observed steps were a result of experimental exror. This examination showed that the system was working properly. This fact combined with the observation that the strain steps were accompanied by a correspondingly slight decrease in load and that the strain steps followed a regular predictable pattern for each test, indicated that the observed phenomenon was real.

Except for several tests performed at high loads, the stepped behavior was not observed on the first quarter of the first cycle, during which the specimen was loaded in tension. In general, the steps first appeared during the compression half of the first cycle, although at low loads the first step was not observed until the specimen had been subjected to a number of stress cycles. It was also observed, for tests at $60 \mathrm{cpm}$, that the strain steps were present for just a few hundred cycles after they first appeared. For most of the specimen lifetime, they were not present. During the 6-cpm tests, once the strain steps appeared, they generally continued for the remainder of the specimen lifetime.

Since the stepped-strain behavior varied so consistently with temperature and load, it can be concluded that the discontinuous strain behavior is dependent on stress level and on stress rate or cyclic frequency. Further study of this phenomenon, its causes and effects, might provide a valuable insight into the problem of deformation and fracture.

The behavior of Inconel as affected by frequency is another interesting phenomenon brought out by this program. The tests at $1500 \mathrm{~F}$ showed for any specified lifetime that specimens cycled at $60 \mathrm{cpm}$ could be subjected to higher stress, greater total strain, and greater plastic strain than could specimens cycled at $6 \mathrm{cpm}$. This suggests that fatigue damage and failure is a function of more than just the gross measurements of the variables of strain or stress. It seems probable that some time-dependent behavior such as local creep or relaxation within the material, which causes deformation, stress redistribution, or other phenomena on a local scale, may be the source of points of weakness which result in the formation of fatigue cracks. Thus, gross measurement of plastic strain or total strain might indicate the tendency toward failure, but this alone is not adequate for accurate prediction of lifetime. 


\section{CONCLUSIONS}

While the limited number of tests and testing conditions studied made it difficult to form any general conclusions concerning the behavior of Inconel during stress cycling, there were some observations which could be made.

(1) Fatigue strength, whether measured in stress, total strain, or plastic strain, was found to be a function of both temperature and frequency.

(2) The relationship between plastic strain and lifetime, represented by $\mathrm{N}^{\alpha} \Delta \varepsilon_{\rho}=\mathrm{K}$, may be approximately valid for Inconel under the conditions studied, although other relations fit the observed data as well, or better.

(3) The relationship between stress and strain, within the range of test conditions and lifetimes studied, varies with cycles of stress reversal, never reaching an equilibrium condition.

(4) The strain behavior of a specimen during stress cycling is not continuous. Strain in the plastic region sometimes occurs in sudden steplike increments, which are predictable functions of temperature, stress, frequency, and cycles.

The work of this program perhaps has raised more questions than it has answered. Further work in this area would be most valuable to help answer some of these questions. One intriguing discovery of the program was the appearance and behavior of the discontinuities in the strain curves. Furthex study of this phenomenon could well be a most valuable addition to knowledge of fatigue behavior. The program also indicated that at high temperatures plastic strain alone does not determine failure, for a frequency effect was found when plastic strain was plotted against lifetime. Thexefore, further study would be valuable to determine whether some other measurable or calculable parameter could be developed which would be independent of frequency, and thus be a suitable measure of fatigue damage. Additional studies of other loading conditions as well as additional study of the data obtained from this program would be useful for evaluating any other parameters which might be considered.

\section{REFERENCES}

(1) Swindeman, R。 W., and Douglas, $P_{a} A_{0}$, "The Failure of Structural Metals Subjected to Strain-Cycling Conditions", Trans. ASME, Series D, 81 (2), 203 (June, 1959).

(2) Coffin, L.F., Jr., "Thermal Stress and Thermal Stress Fatigue", Proceedings for Short Course on Material Engineering for High Temperatures, Pennsylvania State University (1958), p 187.

$\mathrm{RGC} / \mathrm{jch}$ 